\title{
初中英语课堂教学中听力教学的策略分析
}

\author{
陈明助 \\ 六盘水市第二十二中学 \\ D O ::10.32629/jief.v2i1.427
}

[摘 要] 随着教育理念的不断更新, 使得传统的英语教学方法已经不能满足学生对于英语学习的需求。尤其是对于初中阶段教学而言, 初中 学生正处于心理和生理快速发育的时期, 传统的英语教学重点强调了知识的死记硬背以及单词语法的使用规则, 教师只顾着单一的知识灌输, 使得学生不得不适应教师的节奏进行英语学习, 导致了学生英语各项学习不均衡、教师教学质量下降。因此, 老师需专项提升学生听力水准 培养学习积极性, 均衡英语教学效率。

[关键词] 初中英语 ; 课堂教学 ; 听力水平

在英语学习中 “读、写、说、听” 是四项基本技能, 学生需要在教 师教学的过程中掌握对英语的四项技能运用, 用于加强学生未来与人交流 能力, 其中 “听” 是学生运用语言以及积累知识的重要方式。受到传统教 学的影响, 初中英语课堂长期以来秉承着教师语言灌输教学, 此种教学方 法下存在诸多问题, 最重要的一点问题就是教师只重视课堂知识教学, 而 忽略对学生英语听力培养。学生不会结合实际运用语法, 英语综合沟通能 力较差。因此在初中课堂教学中, 老师应加强对英语听力的方法探寻与实 际实施, 提升学生英语综合素养 ${ }^{[1]}$ 。

\section{1 初中英语课堂中存在的问题}

1.1 教师英语专业素养不足

现如今英语教学受到应试考试的影响, 大多数老师对于怎样进行英 语听力教学没有明确方向, 对其理解不足。部分教师认为英语知识语法的 传输比听力更加重要, 可以应付未来应试考试取得理想成绩。而听力教学 培养会分散学生学习集中性, 在英语考试总体分数中仅仅占据 15\%, 浪费 课堂教学时间。因此在传统课堂上教师的注意力便在如何教授学生知识点 与语法方面, 削减了听力教学在初中英语教学任务中的比重。再者, 有的 初中教师的英语专业素养不足, 无法探索全新教学方法来进行创新型课 堂, 更加注重语法知识的提炼与灌输, 轻视听力说写训练, 导致学生英语 沟通逻辑思维能力较弱, 听力测试环节得分不理想。

\section{2 英语新教材听力教学内容偏难}

现如今英语教材经过最新一轮编制, 其中许多语法词汇以及句型在 编写方式上面进行了内容加深, 不仅词汇量加大, 且英语听力和英语文章 具有现代信息化特点, 丰富多变的内容更加体现了与时俱进, 但同时存在 听力难度变难问题。学生无法集中掌握听力短暂时间内所传达信息 ${ }^{[2]}$ 。例 如八年级下册中有训练学生听下列几段对话或独白, 随后回答 “Who did Tom play baseball with?” 与 “What was the most interesting thing for James? ” 等诸多问题, 听力内容中人物过于复杂, 导致学生无法有 效完成听力任务。

\section{2 英语课堂中提升英语教学的策略}

2.1 提升教师素养, 营造活跃教学氛围

为适应新型英语教材更新, 英语老师要时刻更新教学观念, 不应长 时间局限于考试对英语教学带来的影响而选择性的教学, 更应该关注英语 对学生未来发展带来的益处, 让英语学习成为未来沟通主要方式之一, 提 升学生综合能力, 加强综合素质。教师提升自身教学观念后, 要时常对学 生进行听力训练, 持之以恒方能看到教学效果。教师也需要不断改进自己, 例如时常翻阅英文简报和书刊, 多听网络优质课程与教学方法, 从中吸取 经验, 更新时代流行教学内容。利用有益处的网络语言增加教学活跃性, 教师与学生共同进步, 才能使教学课堂不断升华。教师还要具有现代化教
学意识, 将科学技术引入课堂, 熟练利用多媒体增加学生学习兴趣, 播放 有助于听力训练视频, 实时的英语资料播放教学能同时提升听力与语法的 学习。

2.2 对教材内容进行篮选, 优化教学内容

初中英语教师可以对繁琐的教学内容进行篎选, 科学的使用因材施 教教学法, 使教学内容更加精炼化, 针对非常冗长且繁琐的听力文章。教 师可提前对文章进行篮选, 将重点部分截取成对话, 再将句型, 语法, 词 汇容易融入其中降低听力的难度, 从内部优化教学难点。例如, 老师可以 采用不同的教学资源将视频进行剪辑, 或者有视频音频的教学课件, 可以 让学生带入听力训练的教学课堂, 增加对英语听力语境的理解力, 不用再 听繁琐复杂的英语背景内容。若此种教学任务难度大有些教师实施成果不 理想, 可以自备教学课件增加与学生互动性训练学生听力。可以将选择性 听力问题作为教学主体, 设置听力内容可以有简单至繁琐, 层层递进, 当 学生对听力内容有所困惑时可适当降低难度, 让听力训练具有弹性。

2.3 务实基础教学, 加强学生能力

良好的教学基础是开展英语课堂的关键, 首先教师需在课堂上严格 控制学生英语发音、音标认识为基本。让学生从学习之初便打下标准的发 音习惯, 音标教学是否正确了决定学生未来英语学习能力的提升空间, 因 此打下英语良好基础对学生至关重要, 其实教师在课堂中需加强英语语法 训练。不断拓展学生的英语词汇量, 进而加深英语听力训练的技巧, 学生 便可抓住听力内容中的关键信息, 并能进行及时处理, 由此便体现了听力 基础教学的有效性 ${ }^{[3]}$ 。

\section{3 结束语}

总而言之, 学生英语听力能力提升是非常冗长的, 需要教师与学生 共同坚持并且学生在课堂要借助大量的听力训练, 来提升自己的综合能 力。而进行英语教学的最终目的, 是为了增强学生语言技能掌握, 英语表 达情感态度的能力语言知识的掌握, 在此基础上培养学生英语使用能力, 使学生成长为全方面人才。

\section{[参考文献]}

[1]季木兰. 对初中英语阅读课导入方法的思考与实践 [J].科学大众 (科学教育),2020(02):36.

[2]段生军.初中英语阅读教学中读后口语活动设计的有效路径 [J]. 西藏教育,2020(02):24-28.

[3] 汪长梅. 浅谈微课在初中英语教学中的有效利用 [ J]. 名师在 线,2020(06):5- 6.

作者简介: 陈明助（1979），男，汉族，贵州盘县人，大学本科， 一级教师 (中), 长期从事初中英语课堂听力有效教学校本化的研究, 强调学生在课堂要借助大量的听力训练, 来提升综合能力。 